\title{
Air entrainment and mixture distribution in Diesel sprays investigated by optical measurement techniques
}

International I of Engine Research 2018, Vol. 19(1) 120-133 (C) IMechE 2017

Reprints and permissions: sagepub.co.uk/journalsPermissions.nav DOI: $10.1177 / 1468087417742527$ journals.sagepub.com/home/jer (SAGE

\author{
Sebastian Riess ${ }^{1,2}$, Lukas Weiss ${ }^{1,2}$, Andreas Peter', Javad Rezaei ' and \\ Michael Wensing ${ }^{1,2}$
}

\begin{abstract}
Mie scattering, Schlieren technique and Raman spectroscopy are used to analyse air entrainment and mixture distribution in sprays at Diesel engine-relevant ambient conditions. Mixture formation for Diesel, gas-to-liquid Diesel, biodiesel (rapeseed methyl ester) and ethanol is investigated. The utilization of different fuels leads to locally equal mass flow ratios of fuel and ambient gas in the spray. The air entrainment process is dominated by conservation of the total spray momentum flux. Shortly after nozzle exit, the amount of ambient gas in the spray is high enough to make it the dominating component of the flow. Already $7 \mathrm{~mm}$ after the nozzle exit, the mass flow of ambient gas equals the mass flow of fuel. Also, the local mixture distribution in the spray - investigated by means of Raman spectroscopy - is fuel independent. Different physical properties of the fuels do (nearly) not influence the air entrainment and macroscopic mixture formation process, as the differences and the amount of fuel are too small to have a significant effect. Injection pressure and the resulting momentum flux are the dominating parameters of mixture formation. Because of the magnitude of the ambient gas content, the spray can be regarded as a gas jet.
\end{abstract}

\author{
Keywords \\ Diesel, injection, mixture formation, air entrainment, alternative fuels
}

Date received: II May 2017; accepted: 8 October 2017

\section{Introduction}

In Diesel engines, mixture formation is dominated by the injection process. Fuel is brought into the combustion chamber with injection pressures of up to $250 \mathrm{MPa}$, whereby the further increase of up to significantly over $350 \mathrm{MPa}$ is in discussion. ${ }^{1-3}$ The influence of a higher pressure in common rail injection systems is often explained by an improvement of atomization (i.e. smaller droplets) favouring vaporization of the fuel and mixing with the ambient air.

In current activities in the field of automotive research, short-chained alcohols (e.g. methanol, ethanol and butanol) are under investigation as additive components for Diesel fuel or for utilization in dual-fuel concepts. $^{4-10}$ The alcoholic substances have a very high specific oxygen content, high latent heat of vaporization and a low cetane number and show the potential to simultaneously lower $\mathrm{NO}_{\mathrm{x}}$ and soot emissions by lowering process temperatures and enhance oxidation. ${ }^{9,11}$ In addition, such alternative fuels can be produced from biomass worldwide in a high quality and at marketable prices. Analysing the impact of alcoholic fuels with low density, viscosity and surface tension, the same approach of explanation as for the effect of increasing injection pressure is often found to be used: short-chained alcohols with their characteristic physical properties lead to an improved atomization and thus air entrainment. ${ }^{4-7}$

This study aims at analysing the impact of injection pressure and utilization of different fuels (Diesel, gasto-liquid Diesel (GtL-Diesel), rapeseed methyl ester

\footnotetext{
'Lehrstuhl für Technische Thermodynamik (LTT), Friedrich-AlexanderUniversität Erlangen-Nürnberg FAU, Erlangen, Germany

${ }^{2}$ Erlangen Graduate School in Advanced Optical Technologies (SAOT), Friedrich-Alexander-Universität Erlangen-Nürnberg FAU, Erlangen, Germany
}

\section{Corresponding author:}

Sebastian Riess, Lehrstuhl für Technische Thermodynamik (LTT), Friedrich-Alexander-Universität Erlangen-Nürnberg FAU, Am Weichselgarten 8, Erlangen D-91058, Germany.

Email: sebastian.riess@fau.de 
(RME) and ethanol) on mixture formation and air entrainment under Diesel engine-relevant ambient conditions. The investigations are carried out based on optical measurement techniques (Mie scattering, Schlieren technique and Raman spectroscopy). In addition, a physical description of the air entrainment process closely linked to the presented measurements is elaborated.

\section{Theoretical description of air entrainment}

The pressure difference between the injection pressure and the ambient pressure in the combustion chamber leads to a mass flow $\dot{\mathrm{m}}_{\mathrm{f}}$ of fuel exiting the nozzle hole at a velocity $\mathrm{u}_{0}$. The combination of those quantities defines the momentum flux (i.e. spray force) of the injection (see equation (1)). Desantes et al. ${ }^{12}$ use a dimensional analysis applying the Vashy-Buckingham $\pi$-theorem to develop a proportionality relationship of the penetration depth $\mathrm{S}$ as a function of ambient density $\rho_{\mathrm{a}}$, time $\mathrm{t}$ and momentum flux, which is given in equation (2). Application of the continuity equation of a fuel mass flow through a hole of diameter $\mathrm{d}$ driven by the pressure drop $\Delta \mathrm{p}$ between injection and ambient pressures leads to a basic proportionality relationship with exponents for the used quantities which are well known from broadly used spray penetration model equations, for example, those of Wakuri et al., ${ }^{13}$ Naber and Siebers, ${ }^{14}$ Sazhin et al. ${ }^{15}$ or Hiroyasu and Arai. ${ }^{16}$ Those correlations for spray penetration thus include at least implicitly the spray momentum flux and its conservation as a driving quantity throughout mixture formation

$$
\begin{aligned}
& \dot{\mathrm{M}}_{0}=\dot{\mathrm{m}}_{\mathrm{f}} \cdot \mathrm{u}_{0} \\
& \mathrm{~S} \propto \rho_{\mathrm{a}}^{-0.25} \cdot \dot{\mathrm{M}}_{0}^{0.25} \cdot \mathrm{t}^{0.5} \propto \rho_{\mathrm{a}}^{-0.25} \cdot \Delta \mathrm{p}^{0.25} \cdot \mathrm{d}^{0.5} \cdot \mathrm{t}^{0.5}
\end{aligned}
$$

Wakuri et al. ${ }^{13}$ develop their model equation based on a simplified spray model of a stationary injection process under consideration of momentum flux conservation. Naber and Siebers ${ }^{14}$ explicitly refer to this spray model in their investigations on spray penetration. The following simplifications are taken for the model:

1. Rectangular velocity distribution in every distance $\mathrm{x}$ to the nozzle exit;

2. Entrained ambient gas exclusively moves normal to the spray axis outside of the spray;

3. Stationary conditions for the injection, that is, constant nozzle exit velocity $\mathrm{u}_{0}$ and spray cone angle $\theta$;

4. No-slip condition between fuel and ambient gas;

5. Constant ambient density even in the mixture;

6. Cross section $A_{f}$ occupied by fuel is negligible compared to cross section $\mathrm{A}_{\mathrm{a}}$ occupied by ambient gas, which thus equates the total cross section $\mathrm{A}$ of the spray in any distance $\mathrm{x}$ to the nozzle exit (i.e. $\left.\mathrm{A}(\mathrm{x})=\mathrm{A}_{\mathrm{a}}(\mathrm{x})\right)$.
For this model spray, a momentum balance is set up in equation (3) ${ }^{17}$ using the fuel mass flow, the nozzle exit velocity, the axial distance $\mathrm{x}$, ambient gas mass flow $\dot{\mathrm{m}}_{\mathrm{a}}(\mathrm{x})$ and the flow velocity $\mathrm{u}(\mathrm{x})$. The presented equation is based on the assumption that the total momentum flux induced by the injection is conserved. Measurements of the spray force (which is the momentum flux) show that it indeed is constant in axial distance to the nozzle exit. ${ }^{18-20}$ Decreasing spray velocity with growing axial distance to the nozzle exit is compensated by an increase in the mass flow of ambient gas with the fuel mass flow being considered constant in any distance $\mathrm{x}$ in the model spray

$$
\dot{\mathrm{M}}_{0}=\dot{\mathrm{m}}_{\mathrm{f}} \cdot \mathrm{u}_{0}=\left(\dot{\mathrm{m}}_{\mathrm{f}}+\dot{\mathrm{m}}_{\mathrm{a}}(\mathrm{x})\right) \cdot \mathrm{u}(\mathrm{x})
$$

Utilizing the continuity equation for the fuel mass flow $\dot{\mathrm{m}}_{\mathrm{f}}$ and the ambient gas mass flow $\dot{\mathrm{m}}_{\mathrm{a}}$ in combination with equation (3) leads to the spray velocity $\mathrm{u}(\mathrm{x})$ in equation (4), where $A_{0}$ is the geometric cross section of the nozzle hole and $\rho_{\mathrm{f}}$ identifies the liquid fuel density at the nozzle exit (i.e. at ambient pressure). With the dimensionless axial distance $\tilde{\mathrm{x}}$ defined in accordance with Siebers ${ }^{17}$ in equation (5), the mass flow ratio of ambient gas and fuel can be derived as given in equation (6)

$$
\begin{aligned}
& \mathrm{u}(\mathrm{x})=\frac{\mathrm{u}_{0}}{2} \cdot \frac{\mathrm{A}_{0}}{\mathrm{~A}(\mathrm{x})} \cdot \frac{\rho_{\mathrm{f}}}{\rho_{\mathrm{a}}} \cdot\left(\sqrt{1+4 \cdot \frac{\mathrm{A}(\mathrm{x})}{\mathrm{A}_{0}} \cdot \frac{\rho_{\mathrm{a}}}{\rho_{\mathrm{f}}}}-1\right) \\
& \tilde{\mathrm{x}}=\sqrt{\frac{\rho_{\mathrm{a}}}{\rho_{\mathrm{f}}}} \cdot \frac{\mathrm{x}}{\mathrm{d}} \cdot \tan \left(\frac{\theta}{2}\right) \\
& \frac{\dot{\mathrm{m}}_{\mathrm{a}}(\tilde{\mathrm{x}})}{\dot{\mathrm{m}}_{\mathrm{f}}}=\frac{\sqrt{1+16 \cdot \tilde{\mathrm{x}}^{2}}-1}{2} \\
& \frac{\dot{\mathrm{m}}_{\mathrm{a}}(\tilde{\mathrm{x}})}{\dot{\mathrm{m}}_{\mathrm{f}}}=2 \tilde{\mathrm{x}}=2 \cdot \tan \left(\frac{\theta}{2}\right) \cdot \sqrt{\frac{\rho_{\mathrm{a}}}{\rho_{\mathrm{f}}}} \cdot \frac{\mathrm{x}}{\mathrm{d}}
\end{aligned}
$$

For distances much larger than the nozzle hole diameter $(x \gg d)$, equation (6) can be simplified and results in equation (7). Resubstituting $\tilde{\mathrm{x}}$ leads to an equation which can be identified as the Ricou and Spalding air entrainment equation for axis symmetric, turbulent gas jets. ${ }^{21,22}$ The high analogy of stationary sprays (resulting from the injection of liquid fuels) and turbulent gas jets is frequently used in a number of publications. $^{23-27}$

With the continuity equations of fuel and ambient mass flows and the simplified form of the mass flow ratio from equation (7), proportionality relationships for $\dot{\mathrm{m}}_{\mathrm{f}}$ and $\dot{\mathrm{m}}_{\mathrm{a}}$ in dependency of fuel density $\rho_{\mathrm{f}}$, ambient density $\rho_{\mathrm{a}}$, nozzle hole diameter $\mathrm{d}$, pressure drop $\Delta \mathrm{p}$ and spray cone angle $\theta$ can be derived as presented in equations (8) and (9)

$$
\begin{aligned}
& \dot{\mathrm{m}}_{\mathrm{f}} \propto \sqrt{\rho_{\mathrm{f}}} \cdot \mathrm{d}^{2} \cdot \sqrt{\Delta \mathrm{p}} \\
& \dot{\mathrm{m}}_{\mathrm{a}} \propto \sqrt{\rho_{\mathrm{a}}} \cdot \mathrm{d} \cdot \mathrm{x} \cdot \sqrt{\Delta \mathrm{p}} \cdot \tan \left(\frac{\theta}{2}\right)
\end{aligned}
$$


It is remarkable that both mass flows have the same proportionality to the pressure drop $\Delta \mathrm{p}$. Increasing injection pressure without changing any other ambient condition is expected to lead to equal mass flow ratios of fuel and ambient gas in any distance $\mathrm{x}$, as long as higher values of $p_{f}$ do not lead to a change in the spray cone angle $\theta$. If this condition regarding the cone angle is fulfilled, no change in the relative air entrainment with increasing injection pressure is expected - of course penetration and air entrainment occur faster with increasing injection pressure. As equation (7) shows a dependency on the fuel density $\rho_{\mathrm{f}}$, the possibility of an influence of different fuels on the air entrainment process theoretically exists.

\section{Experimental section}

\section{Experimental set-up}

All optical measurements are performed in the hightemperature and high-pressure injection and combustion vessel 'OptiVeP' (Figure 1). This test bench with an inner volume of $10 \mathrm{~L}$ is permanently scavenged with gas, freely adjustable in its composition from air to pure nitrogen. The gas flows through the chamber from the top corners, where it is electrically heated, to the bottom corners, where water coolers are installed. The gas temperature $T_{a}$ and ambient pressure $p_{a}$ can be varied independently up to $1000 \mathrm{~K}$ and from $30 \mathrm{kPa}$ to $10 \mathrm{MPa}$. The velocity of the gas flow in the measurement plane is approximately $30 \mathrm{~mm} \cdot \mathrm{s}^{-1}$. The scavenging gas can thus be regarded static compared to the spreading velocities of fuel sprays during a measurement, although the gas flow is high enough to cart away the injected fuel before the next injection event. This allows investigation repetition rates of up to $3 \mathrm{~Hz}$.

The presented measurements are all conducted at a repetition rate of $1 \mathrm{~Hz}$. For the investigation of an injection event, no signal from the previous injection can be observed (e.g. in the high-speed Schlieren imaging). It can thus be assumed that at this rate, there is no shotto-shot influence for consecutive injection events. The installed Diesel fuel system enables injection pressures $\mathrm{p}_{\mathrm{f}}$ of up to $250 \mathrm{MPa}$ in a common rail system. The fuel temperature $T_{f}$ in the nozzle tip can be controlled in a range from 243 to $373 \mathrm{~K}$ via a thermostat.

At five sides of the cubic chamber body window flanges are mounted, where the quartz glass windows have an accessible diameter of $125 \mathrm{~mm}$. On the bottom side, a flange with an injector housing and intercooler system is installed. The injector used for all experiments has the body of a market available, piezo-driven servo hydraulic common rail injector equipped with a special research nozzle, which has three nozzle holes at an elevation angle of $45^{\circ}$ arranged equidistantly around the nozzle axis. This allows the isolated observance of a

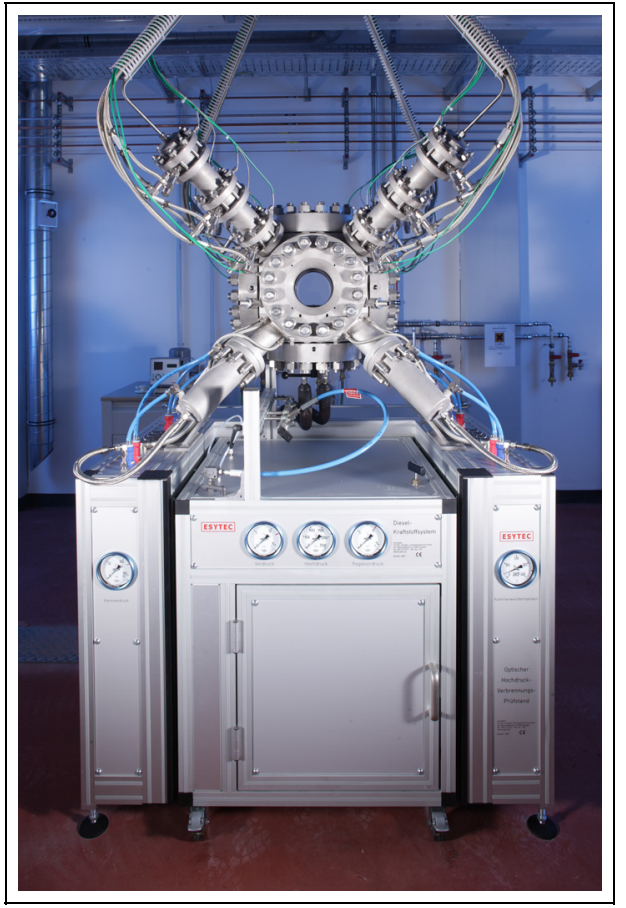

Figure I. High-temperature and high-pressure injection and combustion vessel OptiVeP.

single fuel jet. The hole diameter $\mathrm{d}$ is $115 \mu \mathrm{m}$ with a length-to-diameter ratio of 6.5. A fully programmable electronic drive unit is used for triggering and injection timing $\mathrm{t}_{\mathrm{i}}$.

For the investigation of different fuels and their mixture formation behaviour, a measurement programme consisting of three different thermodynamic operating points is used. The conditions are given in Table 1 and represent a variation of the ambient temperature $T_{a}$.

The different fuels under investigation are fossil Diesel fuel, RME (biodiesel), GtL-Diesel and ethanol (Table 2). To analyse the effect of injection pressure on the liquid phase penetration, at a temperature of $873 \mathrm{~K}$, Mie scattering measurements at values of $\mathrm{p}_{\mathrm{f}}$ of 80, 160 and $200 \mathrm{MPa}$ are performed additionally for Diesel fuel only.

\section{Measurement of injected mass and mass flow rate}

In addition to the optical investigations, the injection behaviour is analysed by means of an injection quantity and rate measuring unit (Moehwald HDA-500) working on the basis of the principal of hydraulic pressure rise. The injected mass and mass flow ratio is measured for injection timings $t_{i}$ of 250,500 and $1000 \mu$ s at an injection pressure of $120 \mathrm{MPa}$ for Diesel and GtLDiesel fuel. Ethanol, RME and Diesel (as reference) are analysed by weighing the total fuel mass injected into a glass flask for 1000 injections in each case for the injection timings mentioned before. 
Table I. Operating conditions for the investigation of mixture formation.

\begin{tabular}{lllll}
\hline $\begin{array}{l}\text { Ambient } \\
\text { pressure } \mathrm{Pa}_{\mathrm{a}}(\mathrm{MPa})\end{array}$ & $\begin{array}{l}\text { Ambient } \\
\text { temperature } \mathrm{T}_{\mathrm{a}}(\mathrm{K})\end{array}$ & $\begin{array}{l}\text { Ambient } \\
\text { density } \rho_{\mathrm{a}}\left(\mathrm{kg} \cdot \mathrm{m}^{-3}\right)\end{array}$ & $\begin{array}{l}\text { Injection } \\
\text { pressure } \mathrm{Pf}_{\mathrm{f}}(\mathrm{MPa})\end{array}$ & $\begin{array}{l}\text { Fuel } \\
\text { temperature } \mathrm{T}_{\mathrm{f}}(\mathrm{K})\end{array}$ \\
\hline 6 & 873 & 22.6 & $80-200$ & 363 \\
6 & 923 & 21.4 & 120 & 363 \\
6 & 973 & 20.3 & 120 & 363 \\
\hline
\end{tabular}

Table 2. Investigated fuels and selected physical properties.

\begin{tabular}{lllllll}
\hline & $\begin{array}{l}\text { Density at } \\
288 \mathrm{~K}\left(\mathrm{~kg} \cdot \mathrm{m}^{-3}\right)\end{array}$ & $\begin{array}{l}\text { Kinematic viscosity } \\
\text { at } 313 \mathrm{~K}\left(\mathrm{~mm}^{2} \cdot \mathrm{s}^{-1}\right)\end{array}$ & $\begin{array}{l}\text { Surface tension at } \\
288 \mathrm{~K}\left(\mathrm{mN} \cdot \mathrm{m}^{-1}\right)\end{array}$ & $\begin{array}{l}\text { Lower heating } \\
\text { value }\left(\mathrm{kJ} \cdot \mathrm{kg}^{-1}\right)\end{array}$ & $\begin{array}{l}\text { Cetane } \\
\text { number }(-)\end{array}$ & $\begin{array}{l}\text { Full boiling } \\
\text { point }\left({ }^{\circ} \mathrm{C}\right)\end{array}$ \\
\hline Diesel & 835 & 2.9 & 24.5 & 43.2 & 54 & 360 \\
RME (biodiesel) & 883 & 4.4 & 29.3 & 39.6 & 54 & 361 \\
Ethanol & 789 & 1.0 & 24.0 & 26.4 & $25-15$ & 78 \\
GtL-Diesel & 776 & 2.5 & 23.6 & 43.7 & 71 & 311 \\
\hline
\end{tabular}

RME: rapeseed methyl ester; GtL-Diesel: gas-to-liquid Diesel.

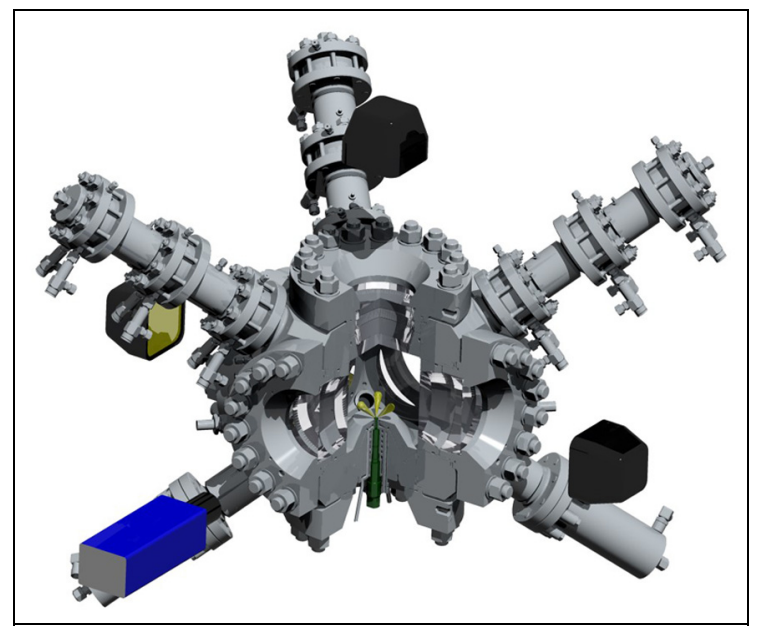

Figure 2. Set-up for measuring elastic Mie scattering at the injection chamber.

\section{Elastic Mie scattering}

For visualization of the liquid fuel phase, a set-up for measuring elastic Mie scattering is utilized (Figure 2). At three sides of the cubic chamber body, stroboscopic flash lamps (Drello HL4090) are installed. A CCD camera (PCO sensicam.qe) with a Zeiss Makro Planar objective ( $\mathrm{f}=100 \mathrm{~mm}$ ) is arranged in such a way that one cone of the three-hole injector is depicted in side view.

The incident light is scattered at the surfaces of liquid drops. Light scattered in the direction of the CCD camera is recorded with an exposure time of $4 \mu \mathrm{s}$ resulting in an intensity greyscale image of the liquid fuel phase. Injection, flash lamps and camera are coordinated temporally, whereby the timing of illumination and image acquisition is successively shifted in discrete time steps to achieve temporal resolution. For every point of time, 32 images are recorded. The measurements are performed in nitrogen atmosphere.

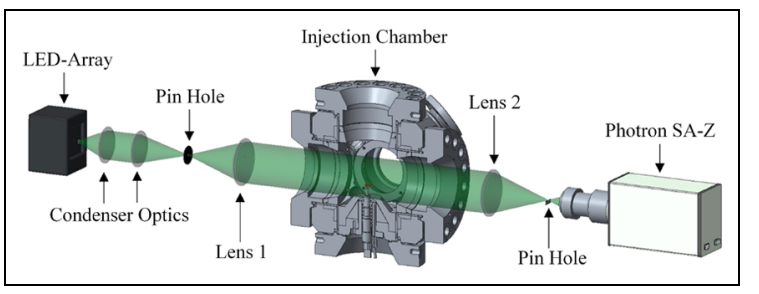

Figure 3. Set-up for measuring Schlieren at the injection chamber.

\section{Schlieren technique}

Schlieren are optical inhomogeneities (e.g. density gradients) in the path of incident light, at which it is refracted because of differences regarding the refractive index. Density gradients - for instance liquid and gaseous fuel in ambient nitrogen - can be visualized utilizing a suitable optical set-up (Figure 3). A LED array emits light in a broad wavelength spectrum around $532 \mathrm{~nm}$, which is collected and shaped by condenser optics and focused in a pin hole. The first apochromatic lens ('Lens 1') collimates the light before passing through the injection chamber. A lens of the same type ('Lens 2') focuses the light to the point where the Schlieren knife edge is located to block strongly refracted light. A pin hole is used for this purpose in the described set-up. The resulting signal is recorded with a high-speed camera (Photron SA-Z) equipped with a Nikon objective ( $\mathrm{f}=220 \mathrm{~mm}$ ) at a frame rate of $40,000 \mathrm{fps}$. For every operating point, 32 injections are continuously captured.

\section{Spray parameters}

For signal images of Mie scattering and Schlieren, penetration depth and spray cone angle are evaluated. All evaluations are carried out with a self-programmed 


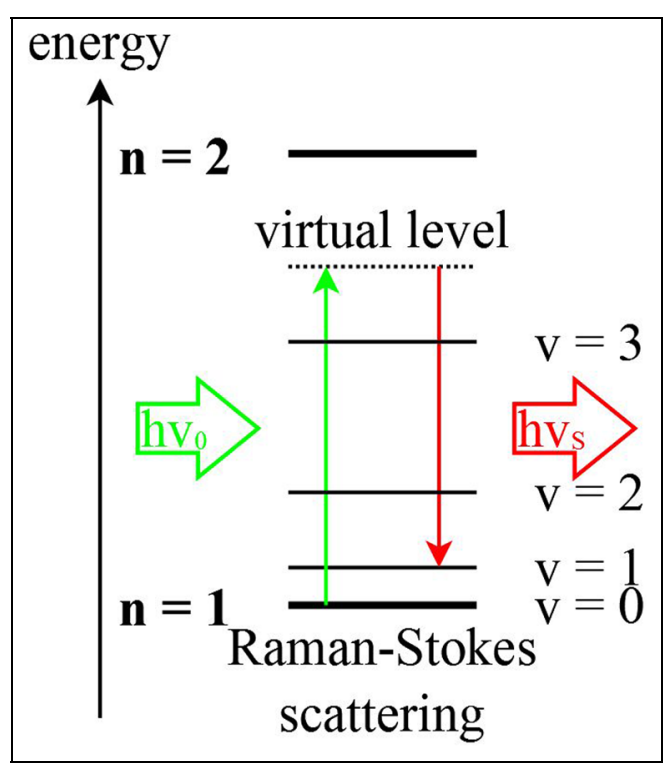

Figure 4. Sketch of the energy level scheme for Raman-Stokes scattering.

MATLAB code. The signal is extracted from the raw image by means of several threshold operations. Penetration depth is defined as the maximum distance of a measurement signal pixel to the nozzle tip. The position of the latter is manually defined before the evaluation by means of a calibration image. For the determination of the cone angle, the geometric centroid of the signal area within an image is utilized. The image is rotated, placing the centroid on the abscissa of a coordinate system with its origin at the manually defined coordinates of the nozzle tip. The outer contours of the signal area in the region between the centroid and the point at half distance between the centroid and the signal pixel with minimum distance to the nozzle tip are determined for both spray parts (i.e. above and below the abscissa). The intersection angle of two straights through the nozzle tip and each outer spray contour is defined as the spray cone angle

$$
\mathrm{V}_{\text {spray }}=\left(\frac{\sqrt{\mathrm{V}_{1}}+\sqrt{\mathrm{V}_{2}}}{2}\right)^{2}
$$

For the Schlieren images, the spray cone volume is evaluated using Guldin's theorem for axis symmetric rotational bodies. Therefore, the image is also rotated in the way described for the determination of the spray cone angle. With the centroid lying on the abscissa, the two-dimensional depiction of the spray cone in the Schlieren image is divided into two parts (above and below the axis). For each of those parts, the volume of a rotational body with the abscissa used as axis of rotation is calculated. The square root mean value of both resulting volumes $V_{1}$ and $V_{2}$ given in equation (10) is utilized to calculate the resulting spray cone volume as it is shown to be the most unsusceptible type of mean value regarding inaccuracy in the determination of the rotational axis. ${ }^{28}$

\section{Raman spectroscopy}

Raman spectroscopy is based on an inelastic process of light-matter interaction. In the set-up used for the presented experiments, the Raman-Stokes scattering signal is detected. For this case of inelastic light scattering, a molecule is elevated by incident laser light from an initial energy level to a virtual energy level, which is located below the next discrete electronic level (quantum number $n$ ) but above vibrational energy levels (quantum number v) with a higher energy than the initial level (see Figure 4).

The virtual energy level is not an actual existing energy level but a hypothetical construct used for illustration of the scattering process in terms of an energy level scheme. Immediately after reaching the virtual level, the molecule falls back to a lower, stable level energetically located above the initial level. In consequence, the scattered light has a different wavelength than the incident laser light.

As it is known from quantum mechanics, the discretely spaced energy levels are substance specific. Therefore, the wavelength of the scattered signal is characteristic for the scattering species, allowing distinction of different substances within the measurement volume. In dependency of the wavelengths of the incident light $\lambda_{1}$ and the scattered light $\lambda_{\text {out }}$, the so-called Raman shift is calculated as given in equation (11) in the unit of a wavenumber $\left(\mathrm{cm}^{-1}\right)$. A Nd:YAG laser (Continuum Powerlite 9030) at a wavelength of $532 \mathrm{~nm}$ is used as light source. The measurements are performed in nitrogen, which has a Raman shift ${ }^{29}$ of approximately $2330 \mathrm{~cm}^{-1}$ for a laser wavelength of $532 \mathrm{~nm}$. Fuel can be identified by the signal of the $\mathrm{CH}$ bound with a Raman shift $\mathrm{t}^{30,31}$ of approximately $2900 \mathrm{~cm}^{-1}$ in this set-up.

$$
\begin{aligned}
& \Delta \omega_{\mathrm{R}}=\left(\frac{1}{\lambda_{1}}-\frac{1}{\lambda_{\text {out }}}\right) \cdot 10^{7} \\
& \mathrm{I}_{\mathrm{R}}=\mathrm{k} \cdot \sigma_{\mathrm{R}} \cdot \mathrm{N}
\end{aligned}
$$

The detected intensity of scattered light $I_{R}$ is directly proportional to the number of scattering molecules $\mathrm{N}$ for every species and the intensity $\mathrm{I}_{0}$ of the incident laser light. Furthermore, it is proportional to the laser frequency $\mathrm{v}_{0}$ in fourth power and to the squared molecular polarizability $\delta \alpha / \delta Q$ of the species. ${ }^{30-32}$ Summing up set-up-specific parameters in a calibration constant $\mathrm{k}$ and introducing the Raman scattering cross-sectional $\sigma_{\mathrm{R}}$, which is proportional to $(\delta \alpha / \delta \mathrm{Q})^{2}$, the scattered signal intensity can be expressed by equation (12).

Figure 5 depicts a sketch of the spray cone in the Raman spectroscopy measurement set-up. The laser light is focused to form a beam waist with a length of approximately $10 \mathrm{~mm}$ along which the scattering signal 


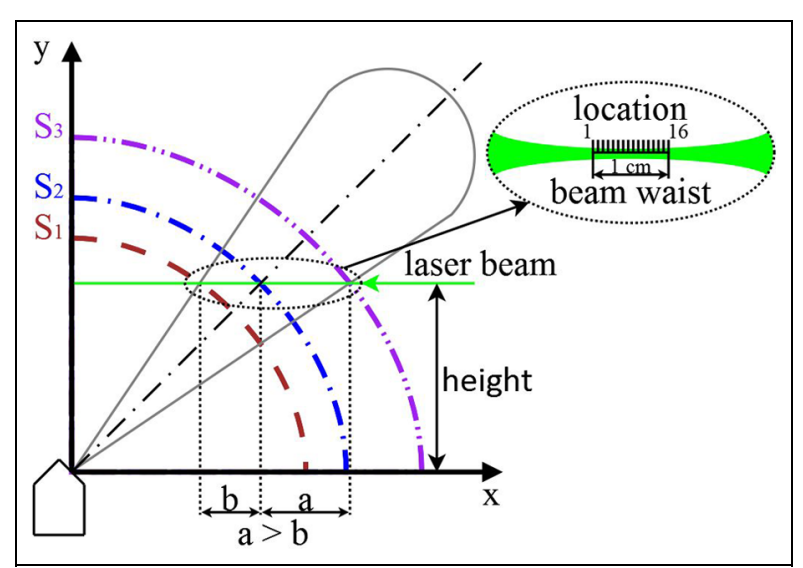

Figure 5. Schematic diagram of the spray cone in the Raman spectroscopy set-up.

is simultaneously recorded at 16 locations. The slit width of the spectrometer is set to $150 \mu \mathrm{m}$ with the diameter of the beam waist ranging in the same order of magnitude. Due to the elevation angle of the nozzle hole and the direction of incident light, an asymmetric section of the spray cone is captured. The optical setup is designed in such a way that the height above the nozzle tip of the incident laser beam and the detection optics including the spectrograph is adjustable. Thus, different heights between 5 and $25 \mathrm{~mm}$ above the nozzle tip are measured to get comprehensive information about the local mixture distributions.

The spectrograph (Andor Shamrock 303i) used in the measurements is equipped with an intensified CCD camera (Andor iStar DH734) operated at an exposure time of $30 \mathrm{~ns}$. Measurements are performed with a temporal resolution in discrete time steps, whereby for every point of time, a minimum of 32 images is recorded.

In the evaluation procedure, all spectra recorded at a point of time are cumulated, baseline corrected via a spline and normalized to the maximum intensity of cumulated signals within all locations and points of time within one measurement point. The $\mathrm{CH}$ peak and the $\mathrm{N}_{2}$ peak of the resulting normalized spectra for every point of time and location are each fitted by a pseudo-Voigt profile. ${ }^{33}$ The areas under these fitted profiles are interpreted as the signal intensities of fuel ( $\mathrm{CH}$ peak) and ambient gas $\left(\mathrm{N}_{2}\right.$ peak). A sample image of cumulated spectra for a measurement of GtL-Diesel fuel at an ambient temperature of $873 \mathrm{~K}$ in a height of $15 \mathrm{~mm}$ above the nozzle tip at $300 \mu \mathrm{s}$ after visible start of injection is depicted in Figure 6.

In this study, results of Raman spectroscopy measurements are displayed by the intensity fraction $\mathrm{I}_{\mathrm{Fr}}$ of fuel given in equation (13) using the detected signal intensities of fuel $I_{R, f}$ and ambient nitrogen $I_{R, N 2}$

$$
\mathrm{I}_{\mathrm{Fr}}=\frac{\mathrm{I}_{\mathrm{R}, \mathrm{f}}}{\mathrm{I}_{\mathrm{R}, \mathrm{f}}+\mathrm{I}_{\mathrm{R}, \mathrm{N} 2}}
$$

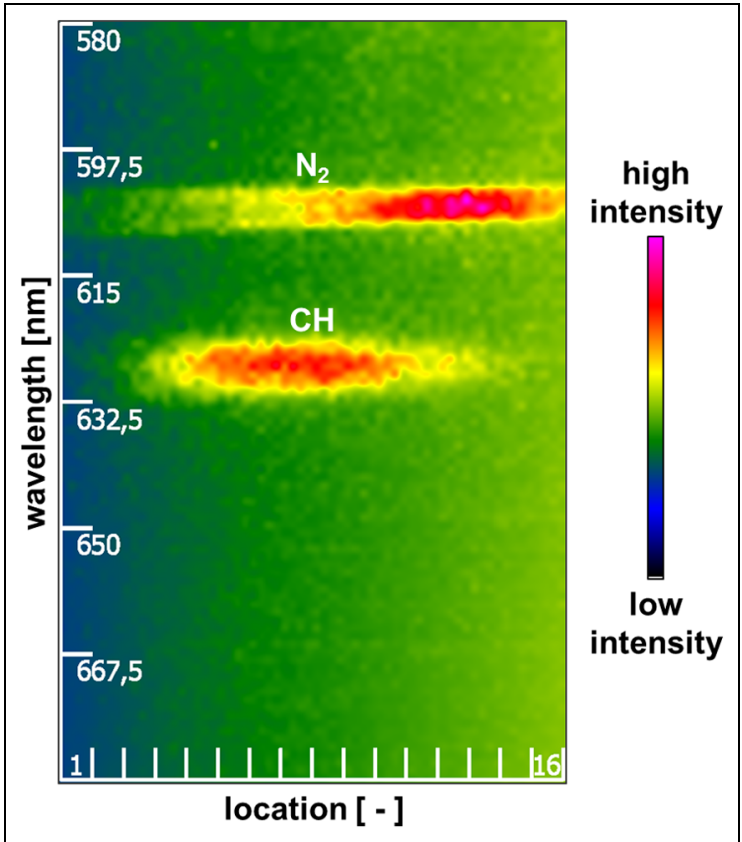

Figure 6. Image of cumulated Raman scattering signal for GtLDiesel at a height of $15 \mathrm{~mm}\left(\mathrm{p}_{\mathrm{a}}=6 \mathrm{MPa}, \mathrm{T}_{\mathrm{a}}=873 \mathrm{~K}, \mathrm{p}_{\mathrm{f}}=120 \mathrm{MPa}\right.$, $\left.T_{f}=363 \mathrm{~K}, \mathrm{t}=300 \mu \mathrm{s}\right)$.

The conventional fossil Diesel fuel contains a considerable amount of aromatics (24.4 wt.\% according to the distributor's certificate of analysis). With the incident laser wavelength of $532 \mathrm{~nm}$ utilized in the experiments, a laser-induced fluorescence signal of the aromatic hydrocarbons occurs. ${ }^{28}$ This signal superimposes the elastically scattered signal in the relevant wavelength interval. For heights below $20 \mathrm{~mm}$, the intensity of the fluorescence signal is higher than the one of the Raman scattering. Only for heights of $20 \mathrm{~mm}$ and higher, the fuel is spatially distributed wide enough, so that the Raman signal can be extracted from the fluorescence background signal by means of baseline correction. Thus, Diesel fuel is only measured at heights of 20 and $25 \mathrm{~mm}$. For ethanol and GtL, no fluorescence signal is detected. They are thus observed at all heights of the Raman spectroscopy experiments. Pure RME is not investigated by Raman spectroscopy.

\section{Measurement results}

\section{Injected fuel mass and discharge coefficients}

The comparison of measured values of total injected fuel mass of Diesel with the HDA measuring unit and the method of weighing fuel mass injected into a glass flask shows a very high accordance. A direct comparison of values measured with both methods for an injection pressure of $120 \mathrm{MPa}$ thus is possible. For injection timings above a $t_{i}$ of $500 \mu s$, only very small differences between the injected masses can be observed for 


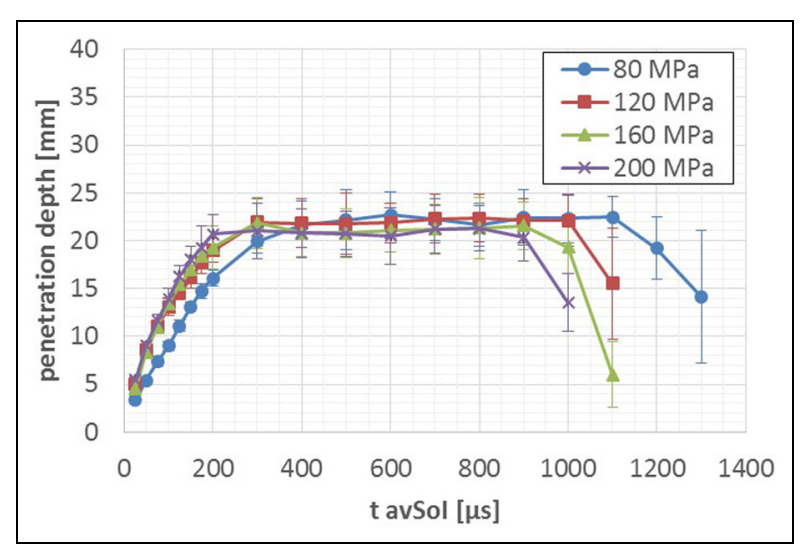

Figure 7. Penetration depths of Diesel sprays at different injection pressures measured with Mie scattering $\left(\mathrm{Pa}_{\mathrm{a}}=6 \mathrm{MPa}\right.$, $\mathrm{T}_{\mathrm{a}}=873 \mathrm{~K}, \mathrm{~T}_{\mathrm{f}}=363 \mathrm{~K}$ ).

different substances. The differences can directly be correlated to a combination of Bernoulli's equation and the continuity equation of mass flow, tracing back to the influence of the square root of fuel density. For the range of engine-relevant fuels in this study, the differences in fuel density of over $100 \mathrm{~kg} \cdot \mathrm{m}^{-3}$ (see Table 2) lead to a maximum deviation of $5 \%$ for ethanol with $t_{i}=500 \mu \mathrm{s}$ compared to the total injected mass of Diesel fuel for the same timing $\left(\mathrm{m}_{\text {Diesel }}=11.30 \mathrm{mg} ; \quad \mathrm{m}_{\text {ethanol }}=10.74 \mathrm{mg}\right)$. Even for fuels with rather different properties such as ethanol and RME, the differences are not big enough to have a relevant impact and thus are insignificant. The discharge coefficient determined on the basis of the injected fuel masses is completely fuel independent.

\section{Spreading of the liquid fuel phase}

Validity of the relations in equations (6)-(9) can be assessed by measurements of the liquid length $\mathrm{L}$, that is, the maximum penetration of liquid fuel. To evaporate a certain amount of fuel, a specific amount of ambient gas has to be entrained into the spray. The complete phase change at the liquid length always takes place, when this characteristic ratio of fuel and ambient mass is reached. If the local mass flow ratio is not influenced by the injection pressure, no change in the value of the liquid length is expected.

A comparison of the penetration depths of Diesel fuel sprays at injection pressures of 80, 120, 160 and $200 \mathrm{MPa}$ measured with Mie scattering technique is depicted in Figure 7. There is no significant difference between the liquid lengths of the sprays. All values lie well within the measurement accuracy that can be assessed by the given error bars. This confirms observations from other measurements of the liquid length for injection pressures of up to over $300 \mathrm{MPa}$. ${ }^{1,34}$ In combination with Figure 8, which shows that the spray cone angle (derived from Schlieren images) is independent of injection pressure, the relationships derived from momentum flux conservation in equations (6)-(9) are

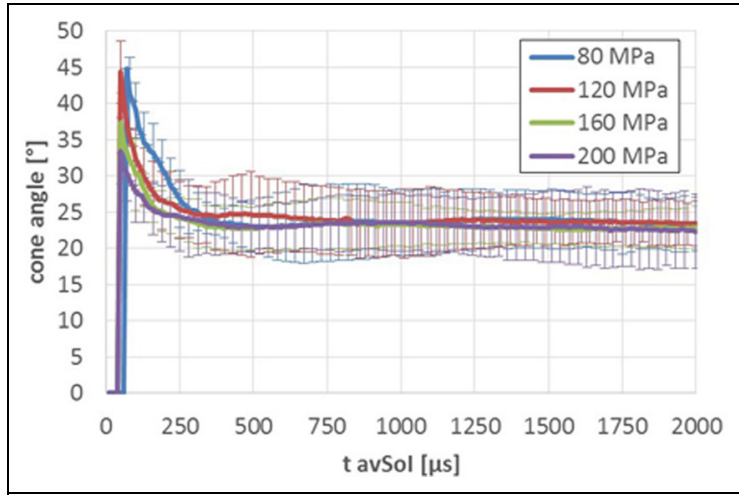

Figure 8. Spray cone angles of Diesel spray in stationary phase measured with Schlieren technique at different injection pressures $\left(\mathrm{Pa}_{\mathrm{a}}=6 \mathrm{MPa}, \mathrm{T}_{\mathrm{a}}=873 \mathrm{~K}, \mathrm{~T}_{\mathrm{f}}=363 \mathrm{~K}\right)$.

confirmed. Differences between the measured curves can be seen in the initial spreading phase of the penetration depth before reaching the liquid length: As the nozzle exit velocity increases with rising injection pressure, the axial spray velocity $\mathrm{u}(\mathrm{x})$ is higher.

Hence, the quality of atomization does not influence the described air entrainment process. Mixture formation is not improved by an increase of injection pressure in a way such that higher mass ratios of ambient gas to fuel are attained locally. The difference lies in the higher spreading velocity by which a certain axial distance and thus, mass flow ratio is reached at an earlier point of time in the injection process.

It has to be remarked at this point that the data presented for the spray cone angle in Figure 8 cannot be compared to the data, which is given in the following for the spray cone angle in the analysis of the fuel influence on mixture formation (e.g. Figure 13). Due to a defect at the nozzle, it was replaced before the measurements presented for the fuel variation. The variation of injection pressure was measured before the replacement. Both nozzles have the identical nominal geometry; however, small quantitative changes regarding penetration depth and spray cone angle occurred due to differences within the limits of manufacturing precision and wear.

A significant influence on the magnitude of the liquid length can be observed for different fuels as Figure 9 illustrates for Diesel (D100), biodiesel (B100), ethanol (E100) and GtL-Diesel (G100). At an ambient temperature of $973 \mathrm{~K}$, RME reaches a maximum liquid penetration of approximately $25 \mathrm{~mm}$. The liquid length measured for ethanol at the same ambient conditions has a value of circa $13 \mathrm{~mm}$. Despite the differences in maximum penetration, all fuels follow the same penetration curve in the initial spreading phase until reaching the individual liquid length.

\section{Spreading of the gaseous fuel phase}

In contrast to elastic Mie scattering, Schlieren technique is capable of measuring both the liquid and the gaseous 


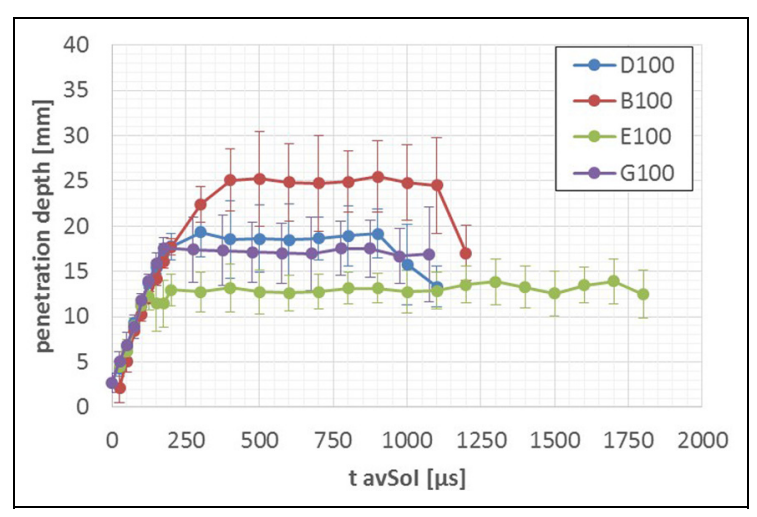

Figure 9. Penetration depths of sprays of different fuels measured with Mie scattering $\left(P_{a}=6 \mathrm{MPa}, T_{a}=973 \mathrm{~K}\right.$, $\left.P_{f}=120 \mathrm{MPa}, T_{f}=363 \mathrm{~K}\right)$.

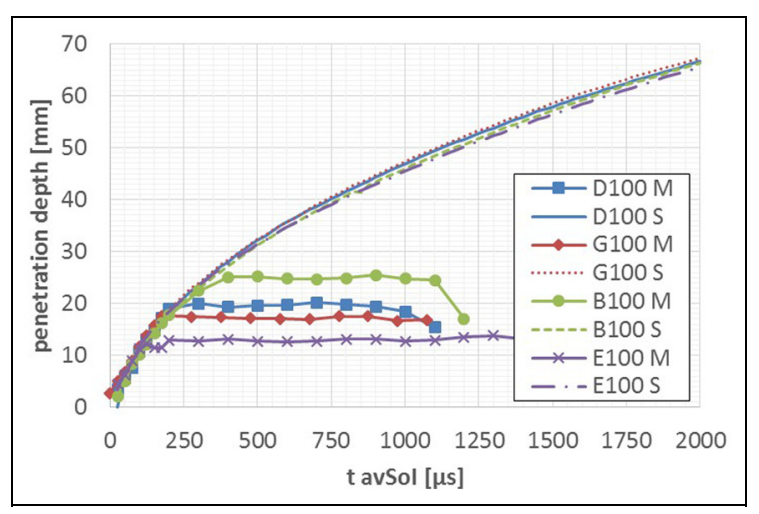

Figure 10. Penetration depths of sprays of different fuels measured with Mie scattering $(\mathrm{M})$ and Schlieren technique (S) $\left(P_{a}=6 \mathrm{MPa}, T_{a}=973 \mathrm{~K}, \mathrm{Pf}_{\mathrm{f}}=120 \mathrm{MPa}, \mathrm{T}_{\mathrm{f}}=363 \mathrm{~K}\right)$.

phases of fuel. Figure 10 presents a comparison of the penetration depths of both measurement techniques for Diesel, GtL-Diesel, biodiesel (RME) and ethanol. The common penetration curve of all fuels, identified before in the Mie scattering measurements, is continued steadily by all fuels. All fuels investigated follow the same spreading curve independent of different physical properties, atomization qualities as well as time and location of the complete phase change as published studies confirm. ${ }^{35-38}$ Furthermore, sprays of all fuels form cones with an equal cone angle (Figure 11). Again, no influence of different fuels can be identified.

Regarding the variation of ambient temperature, neither for the penetration curve nor for the spray cone angle any influence can be found. The change in ambient density related to the temperature variation is not high enough to show any impact.

A first insight into the meaning of those findings for the mixture formation of fuel sprays in engine-like ambient can be gained by balance of the spray volume - derived from Schlieren images - and the fuel volume within the spray based on time-resolved measurements of the injected fuel mass. As can be expected due to the

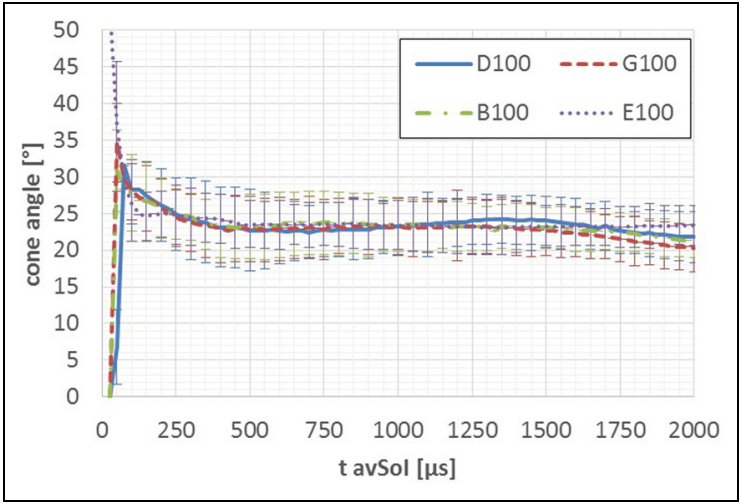

Figure I I. Spray cone angles of sprays of different fuels measured with Schlieren technique $\left(\mathrm{P}_{\mathrm{a}}=6 \mathrm{MPa}, \mathrm{T}_{\mathrm{a}}=873 \mathrm{~K}\right.$, $P_{f}=120 \mathrm{MPa}, T_{f}=363 \mathrm{~K}$ ).

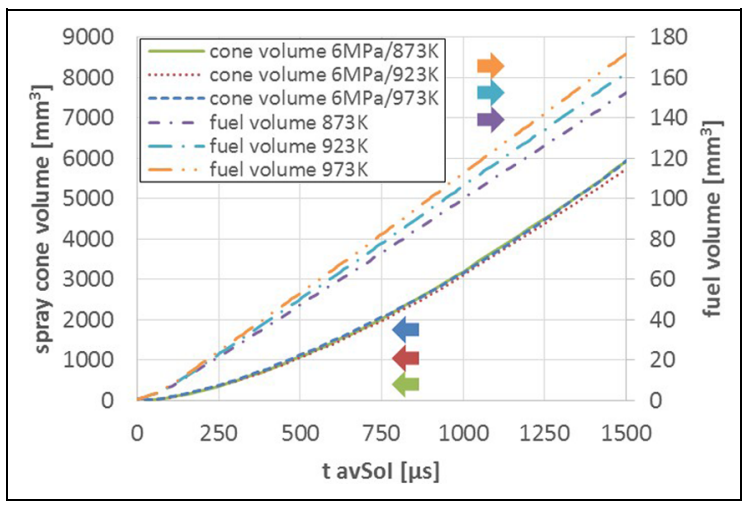

Figure 12. Spray cone volumes and fuel volumes of ethanol sprays at different ambient temperatures $\left(\mathrm{Pa}_{\mathrm{a}}=6 \mathrm{MPa}\right.$, $P_{f}=120 \mathrm{MPa}, T_{f}=363 \mathrm{~K}$ ).

corresponding penetration curves and spray cone angles, there is no significant difference between the derived cone volumes of different fuels and at different ambient temperatures (see Figure 12).

In Figure 12, the bottom curves represent the spray cone volumes, whose values are given on the left ordinate as indicated by the arrows. The top curves are the fuel volumes calculated from the injected mass - determined with the Moehwald HDA-500 measuring unit under the extreme assumption that the fuel has already taken the ambient temperature at nozzle exit. This assumption leads to the maximum fuel volume possible.

The values of the fuel volume curves are shown on the right ordinate as it is indicated by the arrows. The global volume balance in Figure 12 is presented exemplarily for ethanol, as for this pure substance, the necessary values of density in the gaseous phase are available in substance databases. Nevertheless, the following findings also apply to all Diesel-type substances (e.g. pure alkanes). For instance, the physical properties of $n$-dodecane are utilized as a substitute for the multi-component fuels with unknown densities in this consideration. 
Table 3. Coefficients of fitted penetration curve and parameters of fit accuracy.

\begin{tabular}{llllll}
\hline$c_{1}$ & $c_{2}$ & $c_{3}$ & $c_{4}$ & $R^{2}$ & SSE \\
\hline 2.5008 & 4.0685 & 3.7450 & 0.4480 & 1.0000 & $2.1667 \times 10^{-4}$ \\
\hline
\end{tabular}

SSE: sum of squared errors.

Even under the extreme temperature assumption taken for the fuel, the volume of ambient gas (nitrogen) in the spray is significantly higher than the fuel volume; $1500 \mu \mathrm{s}$ after the visible start of injection, the fuel volume of ethanol reaches a value of around $160 \mathrm{~mm}^{3}$, whereas at the same time, the volume of ambient gas is approximately $6000 \mathrm{~mm}^{3}$ and thus 37.5 times higher than the fuel volume.

The ambient gas volume can be calculated as the difference between the spray cone volume and the fuel volume. Under the assumption of constant ambient gas density during the whole injection and mixture formation process, the mass of nitrogen in the spray is derived. According to this calculation, already $50 \mu \mathrm{s}$ after the visible start of injection, there is a higher mass of ambient gas within the spray than there is of fuel. The amount of nitrogen quickly is so high that the different fuel densities, like those of ethanol and n-dodecane, become negligible, and the global mass ratio can be considered fuel independent. Furthermore, the amount of nitrogen is so high that small differences in fuel volume, for example, like in Figure 12 as a consequence of temperature, do not show any impact. Thus, at the investigated ambient conditions, there is no temperature influence on the global mass ratio of ambient gas and fuel either. The change in ambient density, related to the variation of ambient temperature in an engine-relevant range, is too low to show any impact.

The mass flow ratio of ambient gas and fuel resolved over the axial distance can be calculated utilizing equation (6). In addition, the measured penetration curve is fitted mathematically by equation (14)

$$
\begin{aligned}
& \mathrm{S}(\mathrm{t})=\mathrm{c}_{1} \cdot\left(\left(\mathrm{t}+\mathrm{c}_{2}^{2}\right)^{\mathrm{c}_{4}}-\mathrm{c}_{3}\right) \\
& \frac{\dot{\mathrm{m}}_{\mathrm{a}}(\mathrm{x})}{\dot{\mathrm{m}}_{\mathrm{f}}}=\left(\frac{\mathrm{u}_{0}}{\mathrm{u}(\mathrm{x})}-1\right)
\end{aligned}
$$

As there is no significant influence on the penetration curve and the cone angle of the various fuels at the ambient temperatures under investigation, one curve can be found to fit all fuels at all temperatures. The coefficients $c_{1}-c_{4}$ of the calculated fit are given in Table 3 alongside the coefficient of determination $\left(\mathrm{R}^{2}\right)$ and the sum of squared errors (SSE).

The temporal differentiation of this locus of the spray tip leads to a time-resolved velocity development that allows to determine the spray front velocity in dependency of the axial distance to the nozzle. The evaluation of this velocity function for an axial distance of zero leads to the nozzle exit velocity $\mathrm{u}_{0}$. For the resulting set of coefficients (Table 3 ), a value of $220.14 \mathrm{~m} \mathrm{~s}^{-1}$ is calculated. Utilizing the measured fuel mass flow rate in the steady injection phase and equation (15), which is derived from a basic momentum flux balance, the mass flow ratio in any axial distance can be calculated. It has to be remarked that the calculated nozzle exit velocity derived from the spray tip penetration curve is significantly lower than $\mathrm{u}_{0}$ of a stationary spray. Furthermore, the measured penetration curve of the spray front and thus the derived velocity for axial distances $\mathrm{x}>0 \mathrm{~mm}$ do not represent stationary injection conditions as well. The local velocity of fuel in a stationary spray is approximately twice as high as the velocity of the spray front at the same axial location. ${ }^{39}$ However, the nozzle exit velocity and the development of velocity with increasing axial distance to the nozzle cannot be determined from the performed measurements for the stationary case. Utilizing a steady-state fuel mass flow rate and the velocity derived from the spray front penetration can thus be considered as a worst case scenario of a highly throttled injection with a high value of the discharge coefficient.

Utilizing equation (6) to calculate the local mass flow ratio of fuel and ambient gas for a steady-state spray leads to no significant quantitative differences for ethanol and n-dodecane. Although the utilized equation is theoretically dependent on the fuel density, different fuels do not lead to significant changes in the mass flow ratio. Additionally, the results for different ambient temperatures do not show a significant impact of this quantity either. As mass flow ratios calculated by equation (15) with the velocity derived from equation (14) represent a worst case scenario (as explained before), it gives slightly higher values for the mass flow ratio of fuel and ambient gas (nitrogen), that is, indicates less air entrainment than the calculation based on equation (6). Besides that, the results of both, the theoretically derived relation in equation (6) and the measurement-based calculations using equations (14) and (15), confirm the results of the volume balance. Within a short distance after the nozzle exit, a high amount of ambient gas is entrained into the spray. No further than $7 \mathrm{~mm}$ downstream of the nozzle hole, the local mass flow of ambient nitrogen in the spray equals the mass flow of fuel. An impact of the utilization of different fuels cannot be seen as the injection of all fuels leads to the same penetration curves, spray cone angles and in final consequence to locally identical mass flow ratios. Nevertheless, the molar concentrations differ according to different molar masses for different fuels.

Based on the results of the volume balance and the momentum flux balance, the injection of fuel under Diesel-like ambient conditions can be considered independent of physical fuel properties. At injection pressures typical for modern Diesel engines, all fuels atomize in such a high quality that small differences regarding the atomization do not show a significant impact. The differences regarding density of various 


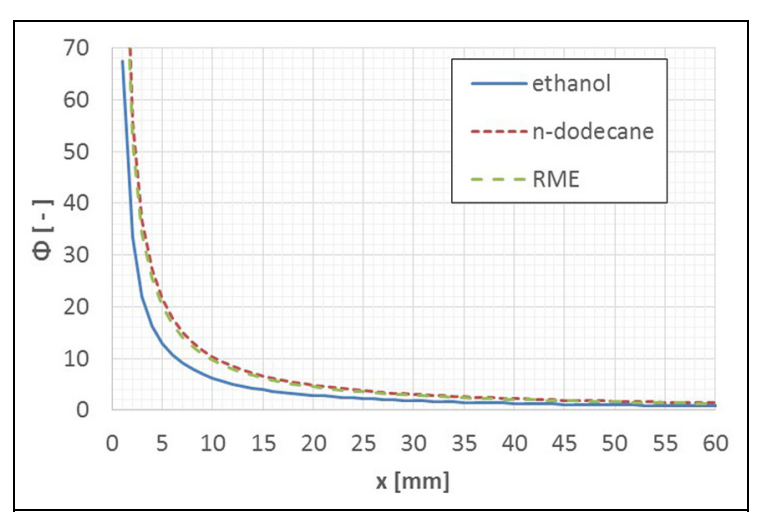

Figure 13. Equivalence ratios of different fuels based on the fuel-independent mass flow ratio calculated by equation (I5).

substances, which can be seen in theoretical description of the air entrainment process, are too small to have any impact. Furthermore, the volume and mass of ambient gas, which are entrained into the spray, are so high that within a short distance and time span, ambient gas becomes the main component of the spray and dominates spray behaviour and further air entrainment. Thus, different fuels with different physical properties and different phase change conditions do not significantly affect penetration and air entrainment.

The influence of different fuels can be seen if the equal mass flow ratios resulting from equation (15) are transformed into molar flow rates and subsequently into equivalence ratios (Figure 13). It is assumed that air has a molar mass of circa 28.9 and behaves exactly like nitrogen regarding mixture formation. The values for RME are calculated for an estimation of the molecular structure of a single 'mean molecule' based on the fuel composition given by the distributor of the fuel. Both oxygenated fuels show an impact on the mixture quality regarding the equivalence ratio. Especially, the short-chained molecule of ethanol with a low molar mass and a high specific content of oxygen has the potential to locally and globally lead to a significantly leaner mixture.

\section{Mixture distribution in the spray}

For all fuels measured with Raman spectroscopy, the same temporal development can be seen at any height. The spray tip and the head vortex of the spray passes the measured height with a different geometrical width and leaner mixtures than the stationary spray. Afterwards, a stationary mixture distribution and composition is reached. In all the following depictions relating to the mixture distribution measured with Raman spectroscopy, for each fuel at each height, a mean curve of all points of time from the stationary mixture state is presented.

The first point of time $t_{1}$ within the stationary phase is given in Table 4 for each height. The period of time from the beginning of the measurement until the

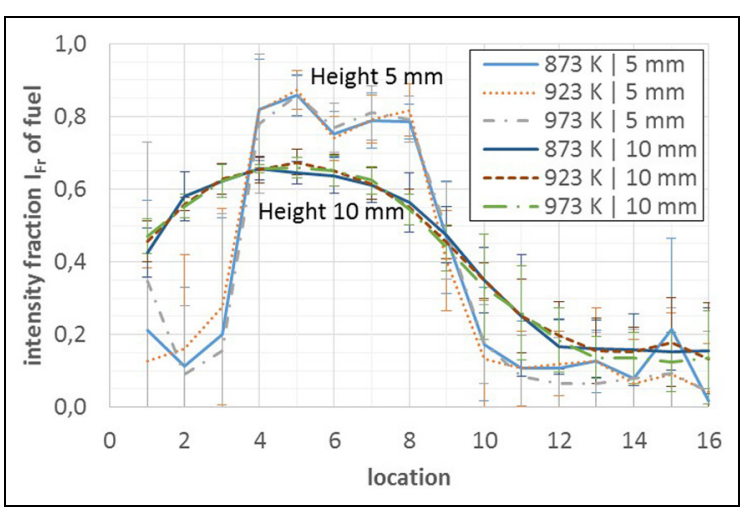

Figure 14. Distribution of intensity fraction of fuel measured with Raman spectroscopy at all ambient temperatures for ethanol at heights of 5 and $10 \mathrm{~mm}$.

Table 4. Temporal beginning of stationary mixture distribution in different heights.

\begin{tabular}{lllllll}
\hline Height $(\mathrm{mm})$ & 5 & 7.5 & 10 & 15 & 20 & 25 \\
$t_{1}$ avSol $(\mu \mathrm{s})$ & 80 & 120 & 180 & 300 & 480 & 700
\end{tabular}

observation of the stationary mixture distribution is measured with a temporal resolution of $20 \mu \mathrm{s}$. As the end of each measurement in any height lies before the closing of the needle, all points of time for $t>t_{1}$ are utilized for the averaging.

Figure 14 shows the intensity fraction of fuel measured with Raman spectroscopy for ethanol in heights of 5 and $10 \mathrm{~mm}$ above the nozzle tip at all ambient temperatures under investigation. However, all findings presented on the basis of the depiction of ethanol are also valid for all other fuels and mixtures. In general, the presented example shows that with increasing height and thus distance to the nozzle, the distribution of the intensity fraction of fuel broadens with a decrease in peak intensity, that is, the local fraction of ambient gas in the mixture increases while the spray propagates radially.

However, the possibility of a direct quantitative comparison of different heights on the basis of the intensity fraction is severely restricted without a calibration measurement for all heights under investigation and thus is not the intended purpose of the data presented in Figure 14. Rather, the presented data are utilized to confirm the findings from Mie and Schlieren measurements regarding the equality of local mass flow ratios independent of ambient temperature. For each temperature, the local mixture distribution at a height shows the same spatial curve. Although there is an ambient density influence in the theoretically derived air entrainment equation, the change in $\rho_{\mathrm{a}}$ in the observed temperature interval of $873-973 \mathrm{~K}$ at an ambient pressure of $6 \mathrm{MPa}$ is too small to show any impact. This is observed for all fuels investigated with Raman spectroscopy at all heights above the nozzle tip. 


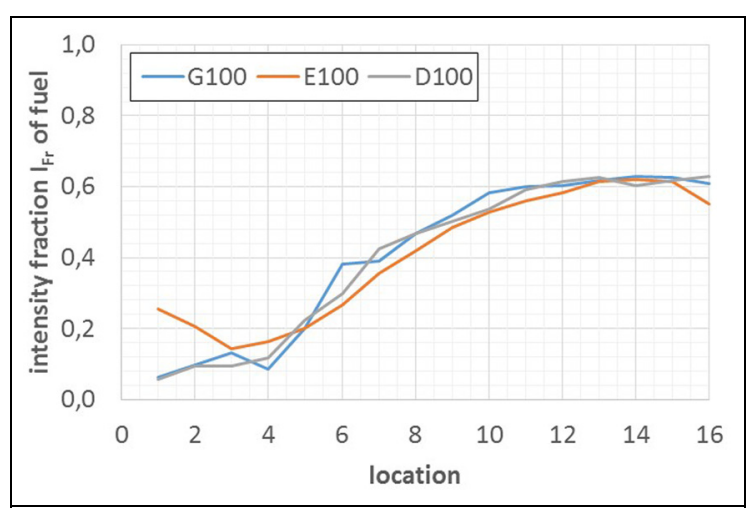

Figure 15. Distribution of intensity fraction of different fuels measured with Raman spectroscopy at an ambient temperature of $923 \mathrm{~K}$ in a height of $20 \mathrm{~mm}$.

The distribution of fuel intensity fraction of the fuels measured with Raman spectroscopy is depicted in Figure 15 in a height of $20 \mathrm{~mm}$. The diagram for this height also includes Diesel fuel (D100), which can only be measured for heights of $20 \mathrm{~mm}$ and above as the fluorescence signal of aromatic hydrocarbons in the fuel at lower heights is too strong to obtain utilizable spectra of the comparably weak Raman scattering signal. It has to be taken into account that the Raman scattering cross section is substance specific; thus, slight differences in the quantitative intensity fraction are expectable. For instance, ethanol has a lower scattering cross section ${ }^{40,41}$ than alkanes, which make up a major part of Diesel and GtL fuels. Beyond that, no influence of fuel on the qualitative mixture distribution can be observed. All fuels show the same qualitative mixture distribution regardless of differences in the physical properties of the substances at each height between 5 and $25 \mathrm{~mm}$ (representing penetration depths between approximately 6 and $50 \mathrm{~mm}$ ). This confirms and expands the findings based on the Schlieren measurements. Furthermore, there is always a scattering signal of a significant amount of ambient gas besides the scattering signal of fuel at any location in any height measured, that is, even at low heights, no region where there is solely fuel without any ambient gas present can be found, even on the spray axis.

With known values for the calibration constants $k_{i}$ and the Raman scattering cross-sectional $\sigma_{R, i}$ of both species, the mole fraction $\mathrm{y}_{\mathrm{f}}$ of fuel can be calculated in dependency of the intensity fraction $\mathrm{I}_{\mathrm{Fr}}$ according to equation (16). In the constantly scavenged combustion vessel, there is no possibility to perform calibration measurements up to now as it is not possible in this setup to fill the measurement volume with a mixture of known composition. For estimation of values regarding the mole fraction, assumptions have to be taken. The ratio of the scattering cross sections of fuel and nitrogen - the so-called relative Raman scattering cross section - is estimated based on published literature. It is known that long-chained alkanes have higher scattering

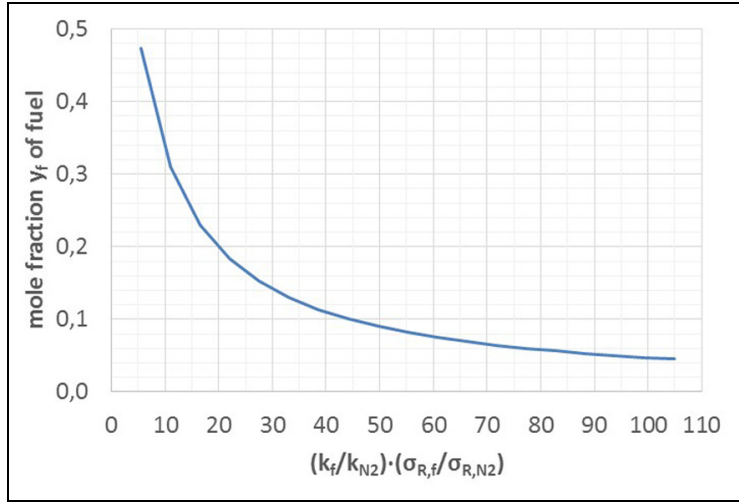

Figure 16. Calculated mole fraction of GtL-Diesel on the spray axis in dependency of calibration constants ratio and scattering cross section in a height of $7.5 \mathrm{~mm}$ at an ambient temperature of $973 \mathrm{~K}$.

cross sections than short-chained alkanes, ${ }^{40}$ and that unbranched alkanes have a lower scattering cross section than branched isomers ${ }^{42}$

$$
\mathrm{y}_{\mathrm{f}}=\frac{\mathrm{N}_{\mathrm{f}}}{\mathrm{N}_{\mathrm{f}}+\mathrm{N}_{\mathrm{N} 2}}=\frac{\mathrm{I}_{\mathrm{Fr}}}{\mathrm{I}_{\mathrm{Fr}}+\frac{\mathrm{k}_{\mathrm{f}}}{\mathrm{k}_{\mathrm{N} 2}} \cdot \frac{\sigma_{\mathrm{R}, \mathrm{f}}}{\sigma_{\mathrm{R}, \mathrm{N} 2}}-\frac{\mathrm{k}_{\mathrm{f}}}{\mathrm{k}_{\mathrm{N} 2}} \cdot \frac{\sigma_{\mathrm{R}, \mathrm{f}}}{\sigma_{\mathrm{R}, \mathrm{N} 2}} \cdot \mathrm{I}_{\mathrm{Fr}}}
$$

Based on the information from the distributor, the shortest unbranched alkane in the GtL-Diesel fuel is n-nonane, whose Raman scattering cross section is taken as the lowest possible for pure GtL-Diesel fuel (G100). The relative scattering cross section of $n-C_{9} \mathrm{H}_{20}$ and nitrogen is estimated to a value of 55 based on publications of Gough and Dwyer ${ }^{40}$ as well as Stephenson. ${ }^{42}$ For a first rough estimation of the mole fraction of fuel, the quotient of both set-up-specific calibration constants is set to unity, as both substances (fuel and ambient nitrogen) in the experiment are measured simultaneously in the identic measurement setup. In a height of $7.5 \mathrm{~mm}$ above the nozzle tip (i.e. an axial penetration of approximately $10.5 \mathrm{~mm}$ ) at an ambient temperature of $973 \mathrm{~K}$, the peak value of the intensity fraction of fuel on the spray axis of $83.2 \%$ represents a mole fraction of $8.2 \mathrm{~mol} \%$ of fuel based on the described assumptions.

Figure 16 depicts the resulting peak value of the fuel mole fraction on the spray axis in dependency of the value of the product of the calibration constant quotient and the relative Raman scattering cross section. Even for a very low value of the product of circa 5.5, still ambient gas is the major constituent of the mixture, as the mole fraction of fuel is $47.3 \mathrm{~mol} . \%$. Thus, in an axial distance of circa $10.5 \mathrm{~mm}$, the major mole fraction of the mixture is already made up by ambient gas, confirming the basic observations of the Schlieren measurements.

Based on the outcome of the Raman spectroscopy measurements in consideration of the results from the Schlieren measurements, not only the mass flow ratio in 
any axial distance can be considered fuel independent but also the local mixture distribution is not influenced by different physical properties of the fuel. The reason for this behaviour is that within a short distance after the nozzle exit, the amount of entrained ambient gas is high enough to represent the major fraction of the mixture and thus dominating the ongoing mixture formation. Even at the lowest height in the measurement of $5 \mathrm{~mm}$, no location, at which there is solely fuel, can be found as a significant scattering signal of ambient nitrogen is measured at any point.

\section{Summary and conclusion}

Mie scattering and Schlieren measurements of sprays of Diesel, GtL-Diesel, RME and ethanol show that the air entrainment in fuel sprays in terms of local mass ratios is independent of the specific physical fuel properties. For all fuels, the volumetric and gravimetric amount of entrained ambient gas within a short distance and time after the nozzle exit is so high that the ambient gas - in case of the presented study nitrogen - becomes the main component of the spray, and the impact of the fuel on the ongoing spray development is found to be very low - negligible in many cases. This finding is supported by a balance of the total spray volume (derived from Schlieren images) and the corresponding fuel volume (derived from measurements of the injected fuel mass). This volume balance shows that the entrained volume of nitrogen in the spray cone is significantly higher than the fuel volume - already $50 \mu$ s after the visible start of injection, there is a higher mass of ambient gas within the spray than there is of fuel. The air entrainment process leading to this characteristic is explained by total momentum flux conservation, for which theoretically derived relations can be correlated to the measurement results with high accordance. The momentum flux balance shows that equal mass flow ratios of fuel and ambient gas occur in any axial distance independent from the injected fuel. The general validity of the equation for the mass flow ratio derived from total conservation of momentum flux can be assessed by an observation based on a variation of the injection pressure $\mathrm{p}_{\mathrm{f}}$. As fuel and ambient gas mass flows show equal proportionality to the injection pressure, the ratio of both is independent of $\mathrm{p}_{\mathrm{f}}$. This is confirmed by measurements of the liquid length by means of elastic Mie scattering for a variety of injection pressures. To evaporate a certain amount of fuel, a specific amount of ambient gas is needed to provide sufficient enthalpy, that is, evaporation takes place when a certain mass flow ratio is reached. As the ratio of mass flows in any axial distance is independent from injection pressure, no change in the location of the complete phase change (i.e. value of the liquid length) can be observed. Air entrainment and phase change are thus not influenced by an increase in the quality of atomization for higher injection pressures in a typical range for modern Diesel engine applications. The gasification of fuel is merely based on and limited by the momentum-driven mass transport of ambient gas into the spray. However, with rising injection pressure, the spreading velocity of the spray is increased, leading to a temporally faster mixture formation, that is, a certain distance to the nozzle is reached within a shorter period of time.

The local mixture distribution for different fuels is investigated by Raman spectroscopy, covering axial distances to the nozzle between 6 and $50 \mathrm{~mm}$. The investigation displays that also the qualitative mixture distribution is independent of the injected fuel in any distance to the nozzle. In addition, nitrogen can be determined in a significant amount even on the spray axis at any measured location within the spray. An estimation of the local quantitative mole fraction of fuel for a penetration depth of around $10.5 \mathrm{~mm}$ verifies that already at this point, the main component of the spray is ambient gas. In total, the presented results show that fuel sprays under Diesel engine-like ambient conditions can be considered fuel independent, have a high analogy to gas jets (as the main component is ambient gas) and can be described by total momentum flux conservation. Different physical properties of fuel and differences in atomization quality do not show any influence on the relative air entrainment. However, fuel-specific differences appear if the globally and locally equal mass ratios are transferred into molar amounts of substances and equivalence ratios. This is due to the specific molecular composition of different substances leading to disparate molecular masses and stoichiometric conditions. In the wake of this, oxygenated fuels such as ethanol show a potential to achieve leaner mixtures. From an engineering point of view, this gives potential to separately develop a suitable mixing process and mass distribution (dominated by the injector geometry and injection conditions but independent of physical properties of the fuel), on one hand, and choose the right combustion characteristics by specifically modifying the fuel (chemical properties) to design an efficient and low-emission combustion concept, on the other hand.

\section{Outlook}

A further improvement of Raman spectroscopy in the special environment of the combustion chamber utilized in this study can be the basis of quantitative analysis of mixture formation in sprays. By improving the optical set-up and thus the intensity and quality of acquired single-shot Raman spectra, mixture distribution and homogeneity could be investigated on a molecular level. This microscopic homogeneity could still depend on specific physical properties of fuels and have an impact on local mixture quality. The investigation will be extended to experiments regarding ignition and combustion of the fuels. 


\section{Acknowledgements}

The authors thank Andreas Braeuer and Tobias Klima for supporting the Raman spectroscopy measurements.

\section{Declaration of conflicting interests}

The author(s) declared no potential conflicts of interest with respect to the research, authorship and/or publication of this article.

\section{Funding}

The author(s) disclosed receipt of the following financial support for the research, authorship, and/or publication of this article: This work was financially supported by the European Community and the Federal State of Bavaria for the project 'Optical high pressure combustion bench test' and by the Federal Ministry of Food and Agriculture (BMEL) in Germany.

\section{References}

1. Johnson JE, Yoon SH, Naber JD, Lee S-Y, Hunter G, Truemner $\mathrm{R}$ and Harcombe $\mathrm{T}$. Characteristics of 3000 bar diesel spray injection under non-vaporizing and vaporizing conditions. In: 12th triennial international conference on liquid atomization and spray systems (ICLASS 2012), Heidelberg, 2-6 September 2012.

2. Wang X, Huang Z, Kuti OA, Zhang W and Nishida K. Experimental and analytical study on biodiesel and diesel spray characteristics under ultra-high injection pressure. Int $J$ Heat Fluid Fl 2010; 31: 659-666.

3. Jia T-M, Li G-X, Yu Y-S and Xu Y-J. Effects of ultrahigh injection pressure on penetration characteristics of diesel spray and a two-mode leading edge shock wave. Exp Therm Fluid Sci 2016; 79: 126-133.

4. Agarwal AK. Biofuels (alcohols and biodiesel) applications as fuels for internal combustion engines. Progr Energ Combust Sci 2007; 33: 233-271.

5. Hansen AC, Zhang Q and Lyne PW. Ethanol-diesel fuel blends - a review. Bioresource Technol 2005; 96: 277-285.

6. Shahir S, Masjuki H, Kalam M, Imran A, Fattah IR and Sanjid A. Feasibility of diesel-biodiesel-ethanol/ bioethanol blend as existing CI engine fuel: an assessment of properties, material compatibility, safety and combustion. Renew Sust Energ Rev 2014; 32: 379-395.

7. Fang Q, Fang J, Zhuang J and Huang Z. Effects of ethanol-diesel-biodiesel blends on combustion and emissions in premixed low temperature combustion. Appl Therm Eng 2013; 54: 541-548.

8. Pan W, Yao C, Han G, Wei H and Wang Q. The impact of intake air temperature on performance and exhaust emissions of a diesel methanol dual fuel engine. Fuel 2015; 162: 101-110.

9. Li Y, Zhang $\mathrm{C}, \mathrm{Yu} \mathrm{W}$ and $\mathrm{Wu} \mathrm{H}$. Effects of rapid burning characteristics on the vibration of a common-rail diesel engine fueled with diesel-methanol dual-fuel. Fuel 2016; 170: 176-184.

10. Ruiz FA, Cadrazco M, López AF, Sanchez-Valdepeñas J and Agudelo JR. Impact of dual-fuel combustion with n-butanol or hydrous ethanol on the oxidation reactivity and nanostructure of diesel particulate matter. Fuel 2015; 161: 18-25.

11. Sayin C. Engine performance and exhaust gas emissions of methanol and ethanol-diesel blends. Fuel 2010; 89: 3410-3415.

12. Desantes J, Payri R, Salvador F and Soare V. Study of the influence of geometrical and injection parameters on diesel sprays characteristics in isothermal conditions. SAE technical paper 2005-01-0913, 2005.

13. Wakuri Y, Fujii M, Amitani T and Tsuneya R. Studies on the penetration of fuel spray in a diesel engine. Bull JSME 1960; 3: 123-130.

14. Naber JD and Siebers DL. Effect of gas density and vaporization on penetration and dispersion of diesel sprays. SAE technical paper 960034, 1996.

15. Sazhin SS, Feng G and Heikal MR. A model for fuel spray penetration. Fuel 2001; 80: 2171-2180.

16. Hiroyasu $\mathrm{H}$ and Arai M. Structures of fuel sprays in diesel engines. SAE technical paper 900475, 1990.

17. Siebers DL. Scaling liquid-phase fuel penetration in diesel sprays based on mixing-limited vaporization. SAE technical paper 1999-01-0528, 1999.

18. Ernst J. Experimentelle und numerische Analyse des Impulses von aufbereitetem Kraftstoffspray im düsennahen Bereich der Dieseleinspritzung. Lehrstuhl Fahrzeugantriebe. Stuttgart: Universität Stuttgart, 2014.

19. Payri R, Garcia J, Salvador F and Gimeno J. Using spray momentum flux measurements to understand the influence of diesel nozzle geometry on spray characteristics. Fuel 2005; 84: 551-561.

20. Payri R, Ruiz S, Salvador F and Gimeno J. On the dependence of spray momentum flux in spray penetration: momentum flux packets penetration model. $J$ Mech Sci Technol 2007; 21: 1100-1111.

21. Ricou FP and Spalding D. Measurements of entrainment by axisymmetrical turbulent jets. J Fluid Mech 1961; 11: $21-32$.

22. Spalding DB. Combustion and mass transfer. New York: Pergamon Press, 1979.

23. Desantes JM, Salvador FJ, López JJ and De la Morena J. Study of mass and momentum transfer in diesel sprays based on X-ray mass distribution measurements and on a theoretical derivation. Exp Fluids 2011; 50: 233-246.

24. Post S, Iyer V and Abraham J. A study of near-field entrainment in gas jets and sprays under diesel conditions. J Fluid Eng: T ASME 2000; 122: 385-395.

25. Cossali G. An integral model for gas entrainment into full cone sprays. J Fluid Mech 2001; 439: 353-366.

26. Andriani R, Coghe A and Cossali G. Near-field entrainment in unsteady gas jets and diesel sprays: a comparative study. P Combust Inst 1996; 26: 2549-2556.

27. Iyer V and Abraham J. Penetration and dispersion of transient gas jets and sprays. Combust Sci Technol 1997; 130: 315-334.

28. Vogel T. Untersuchung der Einspritzung, Gemischbildung, Zündung und Verbrennung unter dieselmotorischen Bedingungen mittels optischer Messtechnik. Aachen: Shaker Verlag, 2016.

29. Rahn LA and Palmer RE. Studies of nitrogen selfbroadening at high temperature with inverse Raman spectroscopy. J Opt Soc Am B 1986; 3: 1164-1169.

30. Luther SK, Schuster JJ, Leipertz A and Braeuer A. Noninvasive quantification of phase equilibria of ternary 
mixtures composed of carbon dioxide, organic solvent and water. $J$ Supercrit Fluid 2013; 84: 146-154.

31. Dowy S, Braeuer A, Reinhold-Lopez K and Leipertz A. Laser analyses of mixture formation and the influence of solute on particle precipitation in the SAS process. $J$ Supercrit Fluid 2009; 50: 265-275.

32. Demtröder W. Laserspektroskopie 2: Experimentelle Techniken. Berlin: Springer-Verlag, 2013.

33. Williams SD, Johnson TJ, Gibbons TP and Kitchens CL. Relative Raman intensities in C6H6, C6D6, and C6F6: a comparison of different computational methods. Theor Chem Acc 2007; 117: 283-290.

34. Siebers DL. Liquid-phase fuel penetration in diesel sprays. SAE technical paper 980809, 1998.

35. Moon S, Tsujimura T, Oguma M, Chen Z, Huang Z and Saitou T. Mixture condition, combustion and sooting characteristics of ethanol-diesel blends in diffusion flames under various injection and ambient conditions. Fuel 2013; 113: 128-139.

36. Desantes JM, Payri R, García A and Manin J. Experimental study of biodiesel blends' effects on diesel injection processes. Energ Fuel 2009; 23: 3227-3235.
37. Kook S and Pickett LM. Liquid length and vapor penetration of conventional, Fischer-Tropsch, coalderived, and surrogate fuel sprays at high-temperature and high-pressure ambient conditions. Fuel 2012; 93: 539-548.

38. Park SH, Kim SH and Lee CS. Mixing stability and spray behavior characteristics of diesel-ethanol-methyl ester blended fuels in a common-rail diesel injection system. Energ Fuel 2009; 23: 5228-5235.

39. Desantes J, Payri R, Salvador F and Gil A. Development and validation of a theoretical model for diesel spray penetration. Fuel 2006; 85: 910-917.

40. Gough KM and Dwyer JR. Effect of structure and conformation on Raman trace scattering intensities in hydrocarbons. J Phys Chem A 1998; 102: 2723-2731.

41. Colles M and Griffiths J. Relative and absolute Raman scattering cross sections in liquids. J Chem Phys 1972; 56: 3384-3391.

42. Stephenson DA. Raman cross sections of selected hydrocarbons and freons. J Quant Spectrosc $R a$ 1974; 14 : 1291-1301. 